\title{
Innovative Concepts in Weaving Technology
}

\author{
N Gokarneshan* \\ Department of Textile Technology, Park College of engineering and technology, India
}

Received: 阱 April 17, 2018; Published: 畊 April 26, 2018

*Corresponding author: N Gokarneshan, Department of Textile Technology, Park College of engineering and technology, Tamil Nadu, India, Email: advaitcbe@rediffmail.co

\begin{abstract}
The article reviews some significant trends in the technology of weaving fabrics. A prototype of multiaxis three dimensional (3D) flat weaving was constructed, and the feasibility of this type of weaving was studied. The current manufacturing methods of weaving 3D performs have been reviewed. The technologies used for composite manufacture by means of weaving technology have been explored. An advanced 2D net shape weaving technology developed with the aim to establish a more cost effective system for the manufacture of dry textile performs for FRPC. A technique has been developed for weaving seamless 3D shapes directly on loom which is an essential step in producing seamless woven garments.
\end{abstract}

Keywords: Multiaxis Weaving; Seamless Garments; 3d Fabrics; Textile Composites; Performs; Cost Effectiveness.

\section{Introduction}

During recent years, a good deal of research into textile structural composites has been conducted for application in defence, space and civilian areas. Because textile structural composite materials are attractive specific properties compared to those of metals. For instance, the NASA-ACT program encouraged the researcher to initiate fibre-based advanced materials, as indicated by Dow and Dexter as well as Dexter and Hasko [1,2]. The use of textiles for technical applications has been on the rise, particularly as composites for engineering purposes. Textiles can provide performance advantages, most notably in terms of high strengthweight ratios compared to metal counterparts [3]; this is ideal for automotive applications, where reduced weight contributes to fuel efficiency and improves ease of handling in the manufacturing process. Textile composites have been defined as "the combination of Ares in system with a textile fibre, yarn or fabric system" [4].

The use of fibre-reinforced polymer composites (FRPC) in structural components has been being attractive to many industry sectors for decades due to their high strength-to-weight and stiffness-to weight ratio as well as high resistance to environmental degradation, which potentially lead to both energy and economic benefits over metal parts [5]. In addition, mechanical properties of FRPC can be optimized for a specific application by tailoring material content as well as orientation of reinforcing fibres in the composite. These advantages, however, can only be provided with very large manufacturing cost premiums at the present. This has been restricted the use of FRPC primarily in relatively low-volume and niche applications such as aerospace or luxury vehicles. In order to support the widespread adoption of these advanced materials, technology advancements are demanded that enable cost-effective manufacture of FRPC for high-volume applications.

Fabrics produced on weaving machines are mostly twodimensional A three-dimensional (3D) woven shape, e.g. a cap, is usually produced by together pieces of 2D woven fabric. This method of producing desired woven 3D has some disadvantages like high labour cost, quality deficiencies of visual technical nature, a large number of potential sources of defects in lay planning, cutting and sewing, lack of reproducibility, wastage of material while cutting, etc. To eliminate these draw backs, methods of producing 3D woven shapes in folded form on looms have been developed. In this method a multilayer fabric is woven shuttle loom whose ends are eliminated progressively during weaving and are subsequently [6-10]. Main drawback of this method is the need of cutting the are progressively eliminated, and slow speed of shuttle weaving machines. 


\section{Innovative concept in multiaxis 3D flat woven fabric}

Traditional textile structural composite materials show better strength and stiffness characteristics than those of metal and ceramics. However, they have a low delaminating resistance which results in catastrophic failure, as reported by Chou, Sih and Skudra [11-14]. 3D woven performs have been developed for composite materials which show a high delaminating resistance and have fracture toughness properties due to z-fibre reinforcement, as reported by Mohamed, Brandt, Drechsler and Arendts, and Cox et al. [15-17]. However, it is understood that z-fibre leads to a reduction in some of its in-plane properties. To improve the inplane properties, additional fibre, which can be called bias, should be introduced to the perform at an angle.

Dow, Dow and Tran field and Skelton developed a fabric structure which has three sets of fibres, two bias fibre sets and a filling which are interlaced with each other to make a single layer tri axial woven [18-20]. However, it has a single layer structure and is highly porous, which is not a result of the high fabric volume fraction or the lack of warp (axial) yarns. Lida et al enhanced tri axial woven fabric in which additional axial fibre was introduced to single layer tri axial woven fabric; this was called a quadrilateral fabric structure [21]. However, the structure is not multilayered in terms of the number of warp, filling and bias layers. Skelton reported that the structure was open and has more isotropic properties compared to those of 2D traditional plain woven [20].

Multiaxis 3D woven performs and a method was developed by Anahara etal. [21-23]. But perform is notversatile in terms of the bias layer position in the perform and is limited in terms of the number of warp layers in the perform. Also the screw shaft system used in bias orientation is not effective due to ineffective bias yarn control during rotation. Kamiya, Popper and Chou reported that instead of using the screw shaft system for indexing bias yarns, guide blocks were used in this technique to orient the bias fibres at $\pm 45^{\circ}$ [24]. This system fairly improves the bias orientation compared to that of the screw shaft system. Farley developed a technique to make a multiaxis structure using individual eye needles [25]. However, the structure lacks z-fibre, and only four yarn sets were interlaced with each other to provide structural integrity. Furthermore, bias insertion is not continuous and must be cut for each bias yarn insertion in the perform, which is not practical.

Mood also developed multiaxis fabric and a method based on the jacquard technique. The structure has four yarn sets which are interlaced with each other to make multiaxis fabric [25]. However, the structure has a single layer and lack of multiple warp and filling layers, which can find only limited application in technical textiles. Mohamed and Bilisik developed multiaxis 3D woven fabric of many warp layers and a method in which tube carriers are used to orient bias fibres at an angle [26-27]. It was found the in-plane shear properties of the multiaxis 3D woven carbon/epoxy composite are better compared to those of the 3D orthogonal woven carbon/ epoxy composite, as reported by Bilisik and Mohamed [28]. Uchida et al made a prototype of multiaxis 3D weaving based on Anahara's guiding block principles in which bias rotation was carried out using the chain-sprocket system, where some of the bias yarns came apart from the structure $[29,30]$. Moreover, the $z$-fibre insertion system not only performs the insertion of z-fibres but also a beatup action, which could damage brittle carbon fibres. This causes the decreasing of some of the mechanical performance of the perform associated with the final composite form. Recently, Bryn, Lowery and Harris, and Nayfeh developed techniques to make multiaxis fabric for use in connectors and joint elements for defence related products $[31,32]$. The fabric has four yarn sets that interlace with each other to form the structure. The fabric is single ply with no z-fibre reinforcement. The process by Bryn, Lowery and Harris has a discontinuous bias insertion. The process by Nayfeh has braider carriers for bias insertion, but the filling insertion and beat-up become impractical.

Multiaxis 3D weaving called "Tube Carrier Weaving" is further developed as part of an extension of previous work conducted by Mohamed and Bilisik [27]. Multiaxis and multilayer performs were enhanced with regard to structure architecture and bias orientation. Multiaxis 3D weaving was prototyped and basic technical hurdles were identified and refined; thus its feasibility was tested. The results were considered to be encouraging for certain types of performs. Multiaxis 3D weaving was prototyped to test the feasibility of the process and the capability of producing various unit cell-based performs [33]. The basic processing parameters were identified related to the perform unit cell. The basic technical hurdle was the beat-up, in which open reed was required for bias orientation in the process, which must be differentiated during the packing action for the width ratio. It was concluded that the process and product of this investigation was considered to be feasible.

\section{New technologies for production of woven 3D textile performs}

Traditionally, composites are manufactured by manual layup of two-dimensional (2D) laminates until the correct thickness and shape is achieved, a costly and labour-intensive method [34]. To overcome these problems, the textile industry has sought to produce near-net-shape reinforced three dimensional (3D) fibre architectures, known as textile performs, which are produced directly into the shape of the final component, eliminating the hand lay-up process. Textile performs can be manufactured by weaving, knitting, braiding, stitching or non-woven methods [35]. 3D contoured performs can be defined as "fully integrated continuous fibre assemblies having multi-axial in-plane and out-ofplane fibre orientation" [36]. Mechanical properties can be tailored by orientating fibres in optimal directions to provide through-thethickness reinforcement, which improves inter laminar shear and prevents delaminating; a characteristic that traditional composites lack $[37,38]$. Textile performs can be injected with resin and subjected to heat and pressure for consolidation into a hard or soft 
(flexible) textile composite; alternatively, they can remain in their soft state for arrange of applications, i.e. padding for sportswear or materials for filtration. The resin contributes only a minor role in the load bearing capacity of the composite [39]; instead, it is the reinforcement materials that provide the strength and load bearing capacity. In a soft composite, the textile structure is the major component to the composite [40]. The production of 3D fabrics through fully automated textile machinery eliminates assembly operations, minimises waste and reduces cost $\mathrm{Hu}$, Ionesietal factors that have led to increased interest in 3D textile performing [41,42]. A significant advantage to 3D performs is their ability to at exactly into a mould for resin infusion without the need to precisely manoeuvre the textile structure into the correct shape. This paper addresses current technologies that achieve such performs, and provides an understanding of how a combination of yarn arrangements (interlocking and interloping) could improve the mechanical and physical properties of a structure. The experimental results of the tensile properties of knit structures with inlay yarns supports further investigations into reinforced contoured material forms.

It has been shown that the use of textile processes for technical applications has been on the rise, and will continue to grow as it makes improvements to products compared to its metal and plastic counterparts. An overview of existing textile technologies, which can produce 3D structures for composite applications has been provided. The benefits and limitations of various construction techniques including their mechanical performance have been highlighted. The need to combine current concept stocreate alternative material forms that has unique mechanical properties such as high strength with good mould ability has been noted. Furthering Abounaim's research of integrating reinforcement yarns in knitted structures will beaky area of interest in the near future [43]. This will allow for performs of almost any 3D shape to be produced instantaneously with reinforcement yarns. It has been proven that the introduction of inlay yarns increases fibre content and improves tensile properties; therefore, further research in this area will enable such structures to compete with woven and braided counterparts for composite applications. It has been found that crimp reduces tensile properties, so minimising the crimp factor of the reinforcement yarns through knitted loops would be ideal. This may cause difficulty during weft insertion, as the width of most knitted fabrics tend to contract when taken off the machine, with the straight weft inlay yarn maintaining its original length causing a high crimp factor. The weft in lay yarns would have to be pulled tight after fabric formation to restrict extension in the weft direction, and an additional process to secure these on the side would need to be undertaken. Alternatively, a knitted structure with high stability and minimal stretch, such as "full cardigan" configuration would need to be used to prevent contraction of the width of the structure. Knitting technology is a diverse and flexible manufacturing method, which is likely to see further growth and development, particularly as an option for light weights of tand hard composites.

\section{Economical Method of Weaving Textile Reinforced Composites}

At the present, utilizing dry textile reinforcement performs in combination with low-cost consolidation processes such as resin transfer moulding (RTM) or vacuum-assisted resin transfer moulding (VARTM) is considered as the most effective manufacturing pathways to achieve low-cost FRPC [44]. In most cases, 2D woven fabrics made of high performance fibres with constant width are used that need to be cut into tailored shaped pieces before being stacked and joined into a matched performing tool with specific shape to meet mechanical and structural requirements. As cut fabric edges are unstable, oversize patterning, skilled hand labor as well as trimming after consolidating are required which consequently make the fabrication of performs and composites expensive. As shown in Figure 1, at least 50\% of FRPC total manufacturing cost is accounted for by performs fabricating $[45,46]$.

To achieve a more cost-effective system for FRPC manufacturing, optimization advances in textile perform fabrication are needed. A promising approach is the implementation of 2D net shape woven fabrics. In contrast to a conventional woven fabric whose width remains constant along the entire length, a $2 \mathrm{D}$ net shape fabric is produced with variable width conforming to a tailored contour so that the desired fabric shape for performing can be achieved solely out of weaving process. Cutting is therefore simplified or even eliminated. Process count, material scrap, tooling and workforce will be reduced which helps to cut down the expensive perform manufacturing cost. Furthermore, a higher grade of automation in perform fabrication can be achieved. Recently, innovative structure concepts of $2 \mathrm{D}$ woven fabrics with tailored contour have been developed and patented by ITM [47]. The described structures show a high potential to be applied in FRPC, however, technical means for their realization is currently missing. With the aim to establish a more cost-effective system for the manufacture of dry textile performs for FRPC, advanced 2D net shape weaving technology has been developed. On the basic of Open Reed Weave (ORW) technology of Lindauer Dornier GmbH, Lindau, Germany, technological and constructive solutions have been carried out to enable the fabrication of $2 \mathrm{D}$ net shape woven fabrics on a broad rapier loom. 2D net shape weaving has been implemented at ITM. A wide variety of $2 \mathrm{D}$ net shape woven contours can be achieved with high geometric precision. Resulting structures show advanced characteristics that can bring both performance and cost advantages to composites fabrication such as globally uniform structural parameters and sufficient edge stability along desired contour.

The development and achievements of advanced 2D net shape weaving have been discussed. Advanced 2D net shape weaving has been developed on the basis of ORW technology. Using available ORW machine, a standard woven fabric with integrated leno 
selvedge in tailored contour can be fabricated. Leno selvedge made of fine multifilament yarn marks the desired fabric shape and keeps the cut fabric pieces from fraying [48]. A variety of leno weave patterns are developed and evaluated in terms of cut edge stability and contour design flexibility. Cut edges with integrated leno selvedge show significant stability improvement compared to that without selvedge. Free form leno selvedge that has a slope angle between $20^{\circ}$ and $90^{\circ}$ relative to weft direction can be realized in a woven fabric made of glass fibre roving 1200 tex. The successful development of 2D net shape weaving using ORW technology helps to establish a more cost effective system for the manufacture of dry textile performs for FRPC. 2D contoured woven fabrics with firm edge can be obtained by weaving so that oversize cutting and hand trimming after moulding are no longer required. In this way material scrap, cycle time and perform manufacturing cost can be reduced significantly. Furthermore, higher grade of automation in perform fabrication can be achieved.

\section{Innovative technique of weaving 3D shapes}

Around 1990, very elaborate and exhaustive work resulted into development of a rapier weaving machine to produce woven seamless 3D hollow shells and some other shapes, without the need of eliminating and cutting warp threads [49-54]. This work produced seamless 3D shapes which are very useful for technical applications• Objective of this work was also to eliminate/minimize making-up by producing seamless woven garments and thereby labour requirement. 3D shapes have been woven in erect fashion and therefore cloth fell does not lie along a line but assumes different shapes on successive picks depending upon profile of shape. Mechanisms of loom becomes complex. Uniform tubular structure cannot be produced due to weft insertion system. Efforts have also been made to produce woven seamless garments on loom without any transverse seams. Most garments have tubular configuration as a part of their structure. Therefore, the development is made on a shuttle loom and seamless clothing's such as trousers, dresses, shirts and blouses are woven. The work described in this paper was initiated in order to develop a simpler weaving technique of producing 3D woven shapes on a shuttle loom. Shuttle loom was employed as uniform tubular configuration; which is very essential for producing most of the garments, can be produced only with shuttle weaving.

The efforts resulted into development of a novel technique of weaving 3D shapes in folded form. This new technique has potential to produce greater verities of 3D seamless woven structures which are essential to produce seamless woven garments. Possible methods of producing 3D woven shapes To produce desired 3D woven shapes two methods are possible: (1) 3D woven shapes are different from 2D shapes with regard to varying spacing of ends and picks in shaped region. Therefore, by creating situation in weaving in such a way that spacing of ends and picks is varied as per shape profile, desired 3D shape can be woven. (2) In 3D shaped region, crossover points do not lie in same plane. Therefore, by creating situation in weaving in such a way that planes of crossover points are shifted from pick to pick according to profile of 3D shape, desired shape can be woven. It is possible to weave desired symmetrical 3D shapes in folded form on handloom as well as on shuttle loom [55]. It is necessary to determine shapes of reed wires according shape profile. Reed with shaped reed wires changes spacing of threads according to profile of 3D shape. Take up rate should also be adjustable, ideally for each end every pick, according to shape profile to produce desired shape. Suitable selected interlacement between warp and weft threads help in generating desired 3D shape. This weaving principle can be extended to produce varieties of seamless woven garments.

\section{Conclusion}

Several multiaxis 3D woven and 3D orthogonal woven unit cells were developed and fabricated for the trial of the performs. Multiaxis weaving units were described and implemented based on the initial trial period. The performance of each unit cell was tested, and important processing parameters were found to be related to the multiaxis unit cell. It was found that this kind of weaving could be achieved for certain types of unit cell, the results of which can be considered to be encouraging. The key textile technologies used for composite manufacture: braiding, weaving and knitting. The various textile performing methods are suited to different applications; their capabilities and end performance characteristics are analysed. Findings - Such performs are used in composites in a wide range of industries, from aerospace to medical and automotive to civil engineering. High production speeds 2Dweavingmachinescanbe easilyadaptedtoproduce3D fabrics various weft insertion methods to allow curved edges. Advances in jacquard mechanics and motors permits variable shedding geometries, and when combined with appropriate weft insertion methods, tail or ended shape performs can be produced. Fixed maximum width slow machine set-up due to warping process.

The woven fabric provides the highest strength and stability, high dimensional stability, high packing density, increased resistance to impact damage and high compressive strength in 3D woven an advanced 2D net shape weaving technology developed with the aim to establish a more cost effective system for the manufacture of dry textile performs for FRPC. 2D net shape weaving is developed based on open reed weave (ORW) technology and enables the manufacture of 2D contoured woven fabrics with firm edge, so that oversize cutting and hand trimming after moulding are no longer required. The introduction of $2 \mathrm{D}$ net shape woven fabrics helps to reduce material waste, cycle time and perform manufacturing cost significantly. Furthermore, higher grade of automation in perform fabrication can be achieved. A new method of weaving seamless 3D shapes has been attempted. Spacing of warp and weft threads varies in shape region with shaped reed wires are developed to change spacing of warp threads. Interlacement pamrwarp and weft 
threads are selected that assists in changing spacing of threads. The new approval: weaving three-dimensional shapes in folded form is developed, that offers advantages over wea: shape in erect form. Findings - The main findings were mathematical determination of shapes of reed wires top • three-dimensional woven shape and weaving shape in folded form. Originality/value it has been shown how three-dimensional shapes are woven in 3D form without the need of eliminating ends.

\section{References}

1. Dow MB, Dexter HB (1997) Development of stitched, braided and woven composite structures. ACT Program and at Langley Research Centre.

2. Dexter HB, Hasko GH (1996) Mechanical properties and damage tolerance of multiaxial warp-knit composites. Composites Science and Technology 56(3): 367-380.

3. Bannister MK (2004) Development and application of advanced textile composites. Proceedings of the Institution of Mechanical Engineers, Part L: Journal of Materials: Design and Applications 218(3): 253-260.

4. Scardino F (1989) An introduction to textile structures and their behaviour, (Eds.), Textile Structural Composites, Cho TW, Ko FK. Elsevier Science.

5. Mills (2001) Composites A 32: 955.

6. Hill H (1916) Improvements in the manufacture of tubular woven fabrics for incandescent mantle foundations, Great Britain, British Patent.

7. Lipper C (1929) Method of making hats and the product thereof, US Patent.

8. Koppelman E (1964) Methods and apparatus for weaving shaped fabrics and articles woven thereby, US Patent.

9. Felix J (1962) Loom for weaving non-cylindrical fabrics, US Patent.

10. McGrath JA, Rheaume WA, Camp man AR (1967) The weaving of threedimensional fabrics for aerospace industry, paper presented at $12^{\text {th }}$ National SAMPE Symposium.

11. Dow MB, Dexter HB (1997) Development of stitched, braided and woven composite structures in the ACT Program and at Langley Research Centre.

12. Dexter HB, Hasko GH (1996) Mechanical properties and damage tolerance of multiaxial warp-knit composites. Composites Science and Technology 56(3): 367-380.

13. Chou TW (1992) Micro structural design of fibre composites. Cambridge University Press, UK 382-390.

14. Sih GC, Skudra AM (1986) Failure mechanics of composites. Elsevier Science Publishers BV.

15. Mohamed MH (1990) Three dimensional textiles, American Scientist 78: 530-541.

16. Brandt J, Drechsler K, Arendts FJ (1996) Mechanical performance of composites based on various three-dimensional woven fiber performs. Composites Science and Technology 56: 381-386.

17. Cox BN, Dadkhah MS, Morris WL, Flint off JG (1993) Failure mechanisms of 3D woven 8 composites in tension, compression and bending. ACTA Metal lurgicaet Materialia 42: 3967-3984.

18. Dow NF (1969) Tri axial fabric. United States Patent Application.

19. Dow NF, Tran field G (1970) Preliminary investigations of feasibility of weaving tri axial fabrics (Do weave). Textile Research Journal 40(11): 986-998.
20. Skelton J (1971) Tri axially woven fabrics: Their structure and properties, Textile Research Journal 41(8): 637-647.

21. Lida S, Ohmori C, Ito T (1995) Multiaxial fabric with tri axial and quart axial portions. United States Patent Application.

22. Anahara M, Yasui Y (1992) Three dimensional fabrics and method for producing the same. United States Patent Application.

23. Anahara M, Yasui Y, Omori H (1993) Three Dimensional fabric with symmetrically arranged warp and bias yarn layers. United States Patent Application.

24. Kamiya R., Cheeseman BA, Popper P, Chou TW (2000) Some recent advances in the fabrication and design of three dimensional textile performs: A review. Composite Science and Technology 60: 33-47.

25. Farley GL, (1993) Method and apparatus for weaving a woven angle ply fabric. United States Patent Application.

26. Mood GI (1996) Multiaxial yarn structure and weaving method. United States Patent Application.

27. Mohamed MH, Bilisik A (1995) Multilayered 3D fabric and method for producing. United States Patent Application.

28. Bilisik A, Mohamed MH (1994) Multi axis 3D weaving machine and properties of multiaxial 3D woven carbon/epoxy composites. The $39^{\text {th }}$ International SAMPE Symposium, USA.

29. Uchida H, (1999) Three Dimensional weaving machines. United States Patent Application.

30. Uchida H, Yamamoto T, Takashima H (2000) Development of low cost damage resistant composites [online], Muratec Murata Machinery.

31. Bryn L, Islam MA, Lowery WL, Harries HD (2004) Three-dimensional woven forms with integral bias fibres and bias weaving loom. United States Patent Application.

32. Nayfeh SA (2006) Bias weaving machine. United States Patent Application.

33. Bilisik AK (2009) New Method of Weaving Multiaxis Three Dimensional Flat Woven Fabric: Feasibility of Prototype Tube Carrier Weaving. Fibres \& Textiles in Eastern Europe 6(77): 63-69.

34. Mouritz AP, Bannister MK, Falzon PJ, Leong KH (1999) Review of applications for advanced three-dimensional fibre textile composites, Composites Part A: applied Science and Manufacturing 30(12): 14451461.

35. Ogale V, Alagirusamy R (2004) Textile performs for advanced composites. Indian Journal of Fibre and Textile Research 29(3): 336-375.

36. Hu J (2008) 3-D Fibrous Assemblies: Properties. Applications and Modelling of Three-Dimensional Textile Structures, Wood head Publishing, Cambridge.

37. Bannister M (2001) Challenges for composites into the next millennium-a reinforcement perspective, Composites Part A: Applied Science and Manufacturing 32(7): 901-910.

38. Hufenbach W, Petrinic N, Hornig A, Langkamp A, Gude M, et al. (2006) Delamination behaviour of 3D-textile reinforced compositesexperimental and numerical approaches, Conference on Damage in Composite Materials: Non Destructive Testing and Simulation, Stuttgart p.1-10.

39. Heenkenda NK (1999) A study of using weft knitted structures for composites, University of Manchester.

40. Annis PA, Quigley JRTW (1998) Flexible textile composite microscopy, in Summer scales, J (Ed.) Micro structural Characterisation of FibreReinforced Composites, Woodhead Publishing Limited, Cambridge p.1754. 
41. Hu H, Zhang M, Fangueiro R, De Araujo M (2010) Mechanical properties of composite materials made of 3Dstitched woven-knittedpreforms Journal of Composite Materials 44(14): 1753-1767.

42. Ionesi D, Ciobanu R., Ciobanu L, Budulan C (2010) Developments of 3D knitted fabrics, $17^{\text {th }}$ International conference Structure and Structural mechanics of Textiles, Technical University, Liberec.

43. Abounaim MD (2011) Process development for the manufacturing of flat knitted innovative 3D spacer fabrics for high performance composite applications, PhD, Dresden University of Technology.

44. Lässig A, Eisenhut M, Mathias A, Schulte R T, Peters F, et al. (2012) Serien production von Hoch festen Faserverbundbauteilen-Perfpektivenfür den Deutschen Maschinen and Anlagenbau (Roland Berger Strategy Consultants).

45. Campbell F C (2004) Manufacturing Processes for Advanced Composites (Oxford: Elsevier Advanced Technology) pp. 303-330.

46. Sköck-Hartmann B and Gries T (2011) Automotive applications of noncrimp fabric composites Non-crimp Fabric Composites-Manufacturing, properties and applications Ed S V Lomov (Cambrige: Woodhead Publishing Limited) chapter 20: 461-480.

47. Cherif C, Hoffmann G, Sennewald C (2015) Gewebe, Verfahren und Vorrichtungzudessen her stellung Patent.

48. DMP Vo, M Kern, G Hoffmann, C Cherif (2017) 2D net shape weaving for cost effective manufacture of textile reinforced composites, $17^{\text {th }}$ World
Textile Conference AUTEX 2017- Textiles - Shaping the Future, IOP Conf. Series: Materials Science and Engineering 254.

49. Buesgen A (1999a) Woven fabrics having a bulging wane and method and apparatus of forming same, Germany, US Patent.

50. Buesgen A (1999b) Woven 3-dimensional shapes-updates and future prospects for new weaving techniques, Melliand English pp. El30-132.

51. Buesgen A (2001) Garments made of tubular components are woven directly without longitudinal or transverse seams by splitting the warp and optionally also the weft, German Patent.

52. Buesgen A (2002) Garment making process involves weaving tubular pieces adapted to body part shape, eg. Legs, arms, German Patent, Patented.

53. Buesgen A (1990) Loom for three dimensional fabrics-gives variable warp lengths and intervals with shapers to give material a durable form, German Patent, Patented.

54. Buesgen A (1993) Weaving loom appliance - enables reed staves to be moved, to open or close the warp as required, German Patent, Patented.

55. Bhattacharya SS, Koranne M (2012) Novel method of weaving threedimensional shapes. International Journal of Clothing Science and Technology 24(1): 56-63.
This work is licensed under Creative Commons Attribution 4.0 License

To Submit Your Article Click Here: Submit Article

DOI: $10.32474 /$ LTTFD.2018.02.000128

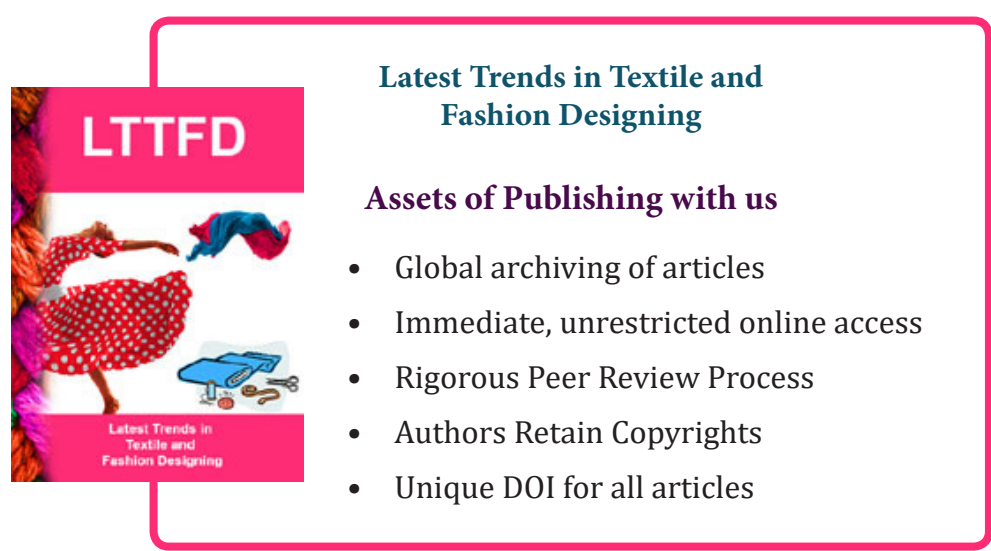

